\title{
PERGAMON
}

www.elsevier.com/locate/watres

\section{SOLAR PHOTOCATALYTIC DEGRADATION OF EIGHT COMMERCIAL DYES IN $\mathrm{TiO}_{2}$ SUSPENSION}

\author{
YIZHONG WANG* \\ State Key Laboratory of Environmental Aquatic Chemistry, Research Center for Eco-Environmental \\ Sciences, Chinese Academy of Sciences, Beijing 100085, People's Republic of China
}

(First received 1 May 1998; accepted in revised form 1 May 1999)

\begin{abstract}
The photocatalytic degradation of eight commercial dyes with different structure and containing different substitute groups has been investigated using $\mathrm{TiO}_{2}$ as photocatalyst in aqueous solution under solar irradiation. Decolorization rate, TOC decrease and inorganic ion production of the dye solution were detected. The experimental results indicate that eight commercial dyes could be degradated efficiently at different levels. The comparison of chloride and sulfate ions production rate from the cleavage of substitute groups in different structure positions reveals the dye compounds degradation pattern and decomposition pathway. (C) 2000 Elsevier Science Ltd. All rights reserved
\end{abstract}

Key words - solar photocatalysis, commercial dyes, decolorization, mineralization, degradation pattern, $\mathrm{TiO}_{2}$

\section{INTRODUCTION}

Dyes are an abundant class of colored organic compounds that represent an increasing environmental danger. During dye production and textile manufacturing processes a large amount of wastewater containing dyestuffs with intensive color and toxicity can be introduced into aquatic systems. Due to the large degree of aromatics present in these molecules and the stability of modern dyes, conventional biological treatment methods are ineffective for decolorization and degradation (Souther and Alspaugh, 1957; Hamza and Hamoda, 1980; Sheng and Chi, 1993. This had led to the study of other methods. Recent studies have demonstrated that photocatalysis can be used to destroy dye compounds using semiconductors such as the anatase form of titanium dioxide and UV light irradiation (Al-Ekabi et al., 1991; Blake, 1994; Hoffmann et al., 1995). Lately, the utilization of combining photocatalysis and solar technologies has been attracted increasing attention. It may be developed to a useful process for the reduction of water pollution caused by dying compounds because of the mild conditions required and their efficiency in the mineralization (Minero et al., 1993, 1996; Daoxin et al., 1994; Lindner et al., 1995; Li and Zhang, 1996). In order to elucidate the photocatalytic decolorization mechanism and decomposition pattern of dye compounds in details, our study focus on the

*Tel.: +86-1-6292-3541; fax: +86-1-6292-3563; e-mail yzwang@mailrcees.ac.cn investigation of inorganic ion production from degradation of substitute groups. It will provide the reaction pathways for eight commercial dyes with different molecular structures and containing different substitute groups under solar irradiation.

\section{EXPERIMENTAL SECTION}

\section{Materials}

Seven commercial dyes were obtained from the Dye Plant in Shanghai without further purification. Methylorange was purchased from the Beijing Chemical Industrial Company as an analytical reagent grade. Their classification and molecular formulas were listed in Table 1. The catalyst used in all testes was titanium dioxide reagent powder (from Beijing Chemical Industrial Company; predominantly anatase with specific surface areas of $9 \mathrm{~m}^{2} \mathrm{~g}^{-1}$ ).

\section{Irradiation experiment}

All photocatalytic experiments were carried out at the same conditions on October 14, 1996 from 11.00 a.m. to 15.00 p.m. The average insolation of the solar irradiation was $21.28 \mathrm{~W} \mathrm{~m}^{-2}$ measured by an UV irradiance meter at the range of $375-475 \mathrm{~nm}$, (model UV-A, made in photoelectric instrument factory of Beijing Normal University). A series of slurries of dyes solution of 11 with $20 \mathrm{mg}^{-1}$ initial concentration and $1 \mathrm{gl}^{-1} \mathrm{TiO}_{2}$ powder were mixed using magnetic stirrers in open Pyrex beakers. A series of certain volume of samples were withdrawn at selected times for analysis. To avoid a volume change due to the volatility of the solvent, a certain amount of distilled water was added into the system at different intervals.

\section{Analytical determination}

Samples were analyzed after centrifugation (1800 rpm for $10 \mathrm{~min}$ ) and filtration by a $0.45 \mu \mathrm{m}$ syringe filter. The 
Table 1. Description of eight commercial dyes

\begin{tabular}{|c|c|c|c|}
\hline No. & Name $\left(\lambda_{\max }\right)$ & Classification & Molecular formulas \\
\hline 1 & reactive brilliant red K-2G $\left(\lambda_{\max }=508 \mathrm{~nm}\right)$ & reactive & $\mathrm{C}_{25} \mathrm{H}_{13} \mathrm{O}_{13} \mathrm{~N}_{7} \mathrm{~S}_{4} \mathrm{ClNa}_{4}$ \\
\hline 2 & reactive brilliant red K-BP $\left(\lambda_{\max }=530 \mathrm{~nm}\right)$ & reactive & $\mathrm{C}_{25} \mathrm{H}_{13} \mathrm{O}_{10} \mathrm{~N}_{7} \mathrm{~S}_{3} \mathrm{Cl}_{2} \mathrm{Na}_{3}$ \\
\hline 3 & reactive yellow KD-3G $\left(\lambda_{\max }=405 \mathrm{~nm}\right)$ & reactive & $\mathrm{C}_{50} \mathrm{H}_{34} \mathrm{O}_{20} \mathrm{~N}_{18} \mathrm{~S}_{6} \mathrm{Cl}_{2} \mathrm{Na}_{6}$ \\
\hline 4 & cationic pink FG $\left(\lambda_{\max }=505 \mathrm{~nm}\right)$ & cationic & $\mathrm{C}_{22} \mathrm{H}_{29} \mathrm{O}_{4} \mathrm{~N}_{2} \mathrm{PCl}$ \\
\hline 5 & methyl orange $\left(\lambda_{\max }=458 \mathrm{~nm}\right)$ & indicator & $\mathrm{C}_{14} \mathrm{H}_{14} \mathrm{O}_{3} \mathrm{~N}_{3} \mathrm{~S}$ \\
\hline 6 & direct light red F-3B $\left(\lambda_{\max }=522 \mathrm{~nm}\right)$ & direct & $\mathrm{C}_{45} \mathrm{H}_{26} \mathrm{O}_{19} \mathrm{~N}_{10} \mathrm{~S}_{6} \mathrm{Na}_{6}$ \\
\hline 7 & direct light turquoise GL $\left(\lambda_{\max }=620 \mathrm{~nm}\right)$ & direct & $\mathrm{C}_{32} \mathrm{H}_{14} \mathrm{O}_{6} \mathrm{~N}_{8} \mathrm{~S}_{2} \mathrm{Na}_{2}$ \\
\hline 8 & acid red $\mathrm{B}\left(\lambda_{\max }=513 \mathrm{~nm}\right)$ & acid & $\mathrm{C}_{20} \mathrm{H}_{12} \mathrm{O}_{7} \mathrm{~N}_{2} \mathrm{~S}_{2} \mathrm{Na}_{2}$ \\
\hline
\end{tabular}

color removal of the dye solution was determined with the absorbance value at the maximum of the absorption spectrum for every dye by monitoring UV/VIS spectrum in 200-800 nm using a spectrometer (Beckman DU-650). The production of ions during photocatalytic degradation process was measured with a capillary ion analyzer (Waters CIA). The total organic carbon of the dye solution was determined with a TOC analyzer (Shimadzu TOC-500).

\section{RESULTS AND DISCUSSION}

\section{Photocatalytic degradation of eight dyes}

The experimental data of different photocatalytic degradation of eight dyes with different structures after $4 \mathrm{~h}$ solar irradiation are shown in Table 2 . It indicates that, in general, the decolorization rate of the dye solution was more rapid than the mineralization rate identified by TOC removal. The latter will take longer time for further oxidation. The release of chloride ions and sulfate ions points to molecular structure cleavage during the solar photodegradation process. Nitrate and nitrite ions were detected in trace quantities in the degradation process of methylorange.

Photocatalytic oxidation of dyes with chloride substitute

Four dyes with chloride-substitutes in different positions listed in Table 1 from Nos. 1-4 are reactive brilliant red $\mathrm{K}-2 \mathrm{G}$, reactive brilliant red $\mathrm{K}-2 \mathrm{BP}$, reactive yellow KD-3G and cationic pink FG, respectively. The chlorides of compound Nos. 1 and 3 are linked to the 1,3,5-triazine ring only. For compound No. 2, one chloride connects with the benzene ring and the other one connects with the triazine ring being the same as compounds Nos. 1 and 3. For compound No. 4, the chloride is linked to the aliphatic lateral chain connected with the nitrogen atom. The results of decolorization (Fig. 1) and TOC decrease (Fig. 2) provide the degree of photodegradation and mineralization for the four dyes with different structures during $4 \mathrm{~h}$ of solar irradiation. The chloride ion production rate (Fig. 3) reveals their degradation pattern. For the compounds Nos. 1 and 3, after $4 \mathrm{~h}$ of solar irradiation, there is no chloride ion detected although the color removal of the dye solution is almost complete $(100$ and $81.34 \%$, respectively) and the TOC content decreased to 81.81 and $41.62 \%$, respectively. The results indicate that the chloride being linked to the triazine as well as the ring structure containing three nitrogen atoms are stable in photocatalysis. Therefore, from the chloride ion production of compound No. 2, we could conclude that it is due to the cleavage of the chloride connected with the benzene ring. It is worth noting that there is a different chloride ion production rate for compound Nos. 2 and 4. Cleavage of the chloride is linked to the benzene ring in compound No. 2 started after 1 $\mathrm{h}$ of irradiation and increased slowly up to $10 \%$ until $4 \mathrm{~h}$ when the TOC degradation of the solution achieved about $72.52 \%$. Clearly, benzene and chloro-benzene are stable intermediate products during the photocatalysis. It requires a longer time for full oxidation. In contrast, for compound No. 4, the chloride ion production rate delayed the rate of decolorization and the TOC decrease and started after $3 \mathrm{~h}$ but increased rapidly up to $36.01 \%$ in the last one hour. It reveals that the chloride group cleavage depends on its position in the molecular structure.

\section{Photocatalytic oxidation of the dyes with sulfonic groups}

The reactive brilliant red $\mathrm{K}-2 \mathrm{G}$ and the reactive

Table 2. Photocatalytic degradation data for eight dye solutions after $4 \mathrm{hr}$ solar irradiation

\begin{tabular}{lccccc}
\hline No. & Name of dye & $\begin{array}{c}\text { Removal of color } \\
(\%)\end{array}$ & $\begin{array}{c}\text { Removal of TOC } \\
(\%)\end{array}$ & $\begin{array}{c}\text { Sulfate ion production } \\
(\%)\end{array}$ & $\begin{array}{c}\text { Chloride ion production } \\
(\%)\end{array}$ \\
\hline 1 & reactive brilliant red K-2G & 100 & 82 & 53 & 0 \\
2 & reactive brilliant red K-2BP & 93 & 73 & 25 & 0 \\
3 & reactive yellow KD-3G & 81 & 42 & 0 & 36 \\
4 & Cationic pink FG & 100 & 61 & 60 & 0 \\
5 & Methylorange & 94 & 52 & 25 & 18 \\
6 & direct light red F-3B & 100 & 40 & 63 \\
7 & direct light turquoise GL & 92 & 55 & & 0 \\
8 & acid ded B & 100 & & & \\
\hline
\end{tabular}




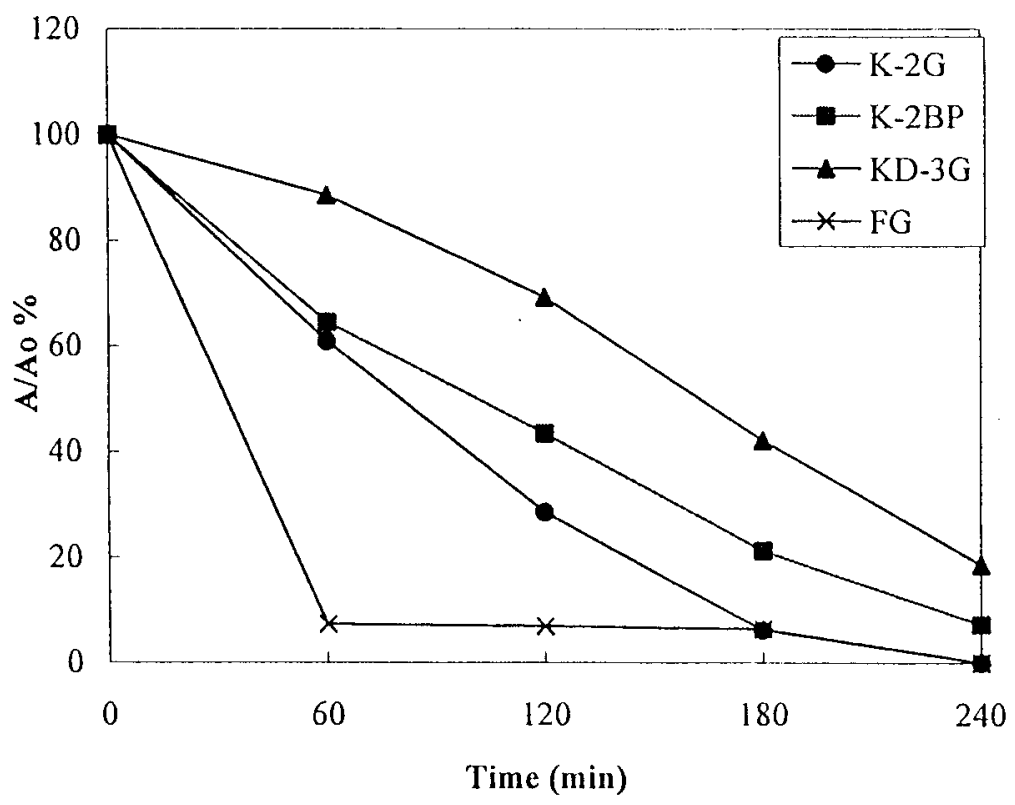

Fig. 1. Color removal of four dyes during $4 \mathrm{~h}$ of photocatalytic oxidation.

brilliant red K-2BP were also chosen as model compounds to investigate the photocatalytic degradation of the dyes containing sulfonic groups. There are three sulfonic groups in a molecule of reactive brilliant red $\mathrm{K}-2 \mathrm{BP}$. They are linked to a naphthalene ring and a benzene ring, respectively. There are four sulfonic groups in one molecule of reactive brilliant red $\mathrm{K}-2 \mathrm{G}$. In addition to the three sulfonic groups, which are the same as those of reactive brilliant red $\mathrm{K}-2 \mathrm{BP}$, the other sulfonic group is linked to another benzene ring, which is not adjacent to the azo bond. According to the results as shown in Fig. 4, the sulfate ion production rates for both dyes within $4 \mathrm{~h}$ show obviously different and the sulfate ion conversion for sulfonic groups are about 28 and $4 \%$, respectively, for the first $2 \mathrm{~h}$. Clearly, the rapid appearance of sulfate ion for reactive brilliant red $\mathrm{K}-2 \mathrm{G}$ is due to the cleavage of the special sulfonic group being different from the others in reactive brilliant red $\mathrm{K}$ 2BP. It is more reactive to photocatalysis than the other three sulfonic groups. The net amount of sulfate ion conversion is about $24 \%$ which is the expected quantity for the photocatalyzed oxidation

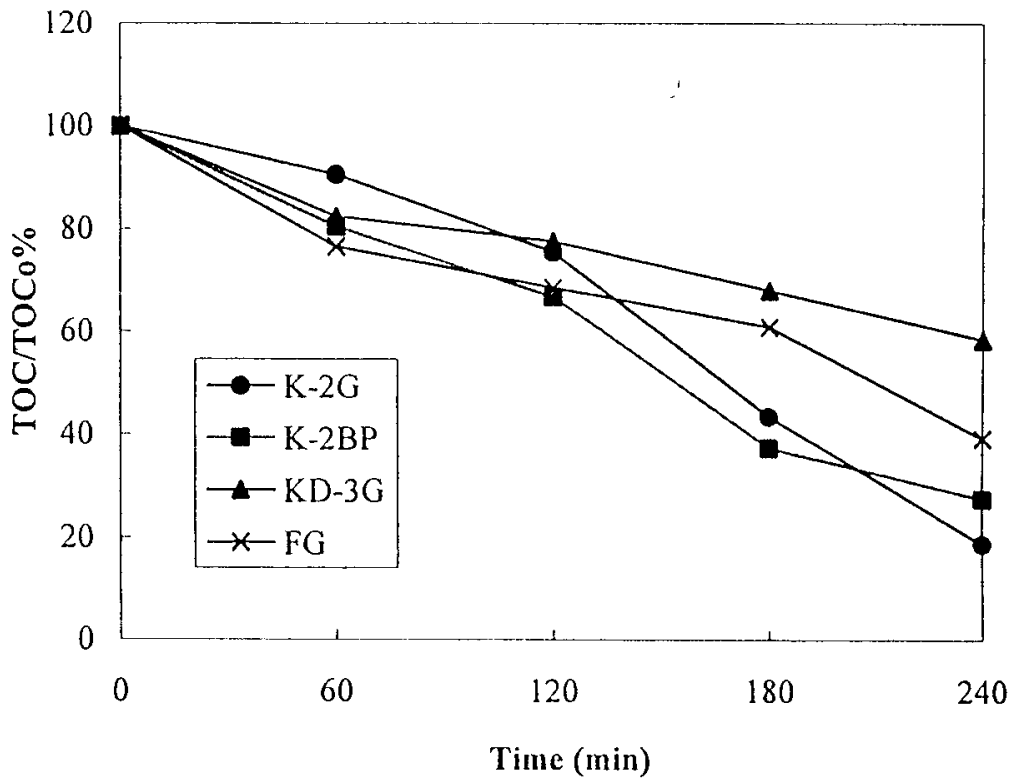

Fig. 2. TOC removal of four dyes during $4 \mathrm{~h}$ of photocatalytic oxidation. 


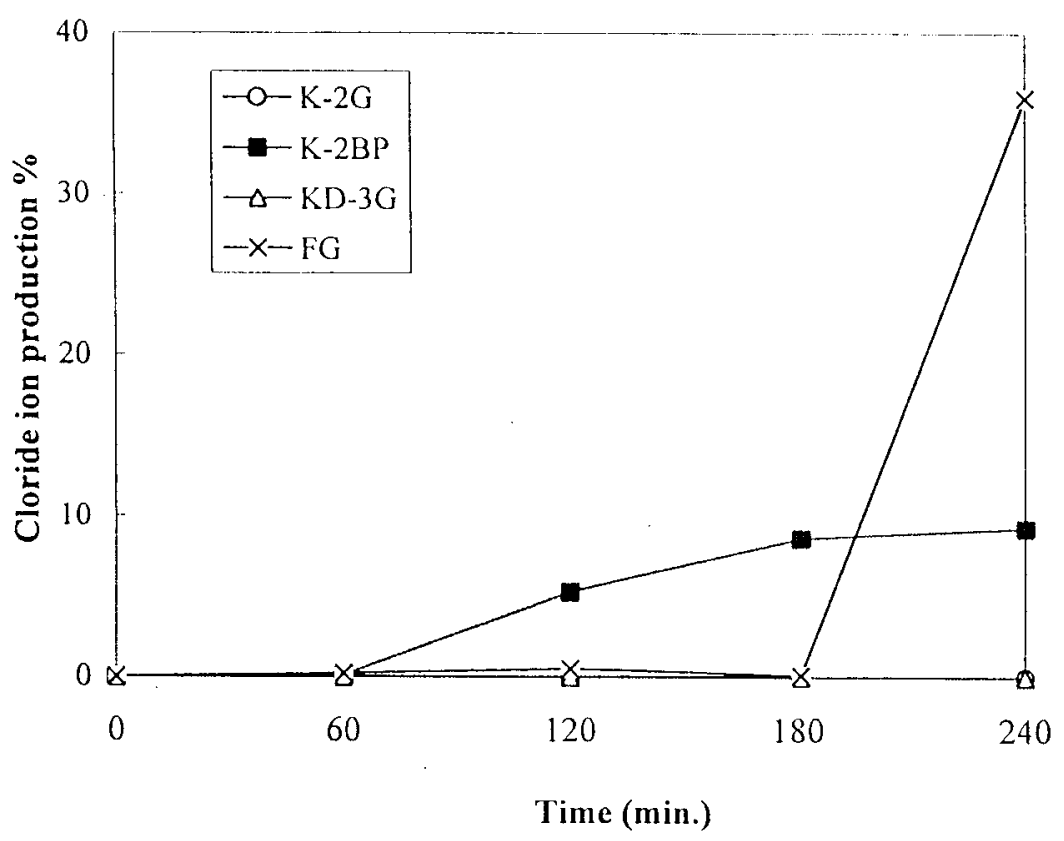

Fig. 3. Chloride ion production of four dyes during $4 \mathrm{~h}$ of photocatalytic oxidation.

of one sulfonic group only rather than the total four sulfonic groups in the whole molecule. It indicates that this kind of sulfonic group degraded before the others. After $2 \mathrm{~h}$, the rate of sulfate ion production is similar.

In the photocatalytic degradation of the acid red B, compound No. 8 according to the molecular formula in Table 1, the two sulfonic groups connect with the two kinds of naphthalene rings wich are with or without a hydroxyl group. From the results shown in Fig. 5, the sulfate ion production rates in the early part and the latter part of irradiation are obviously different. It reflects the difference in reactive property between two naphthalene ring structures. It still needs further identification of the other products in order to determine which naphthalene ring is more reactive in photocatalysis.

Comparison of photocatalytic decolorization of dyes with different substitute groups

The molecular structures of reactive brilliant red $\mathrm{K}-2 \mathrm{G}$ and reactive brilliant red $\mathrm{K}-2 \mathrm{BP}$ show differ-

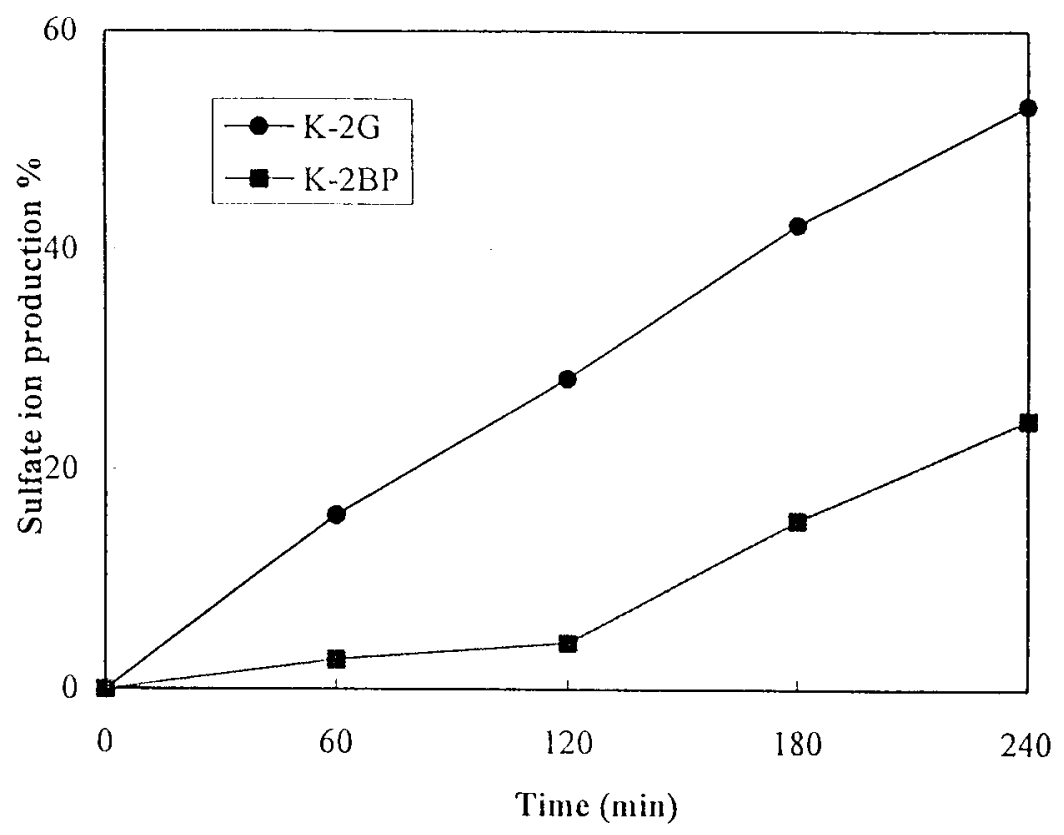

Fig. 4. Sulfate ion production for two dyes during $4 \mathrm{~h}$ of photocatalytic oxidation. 


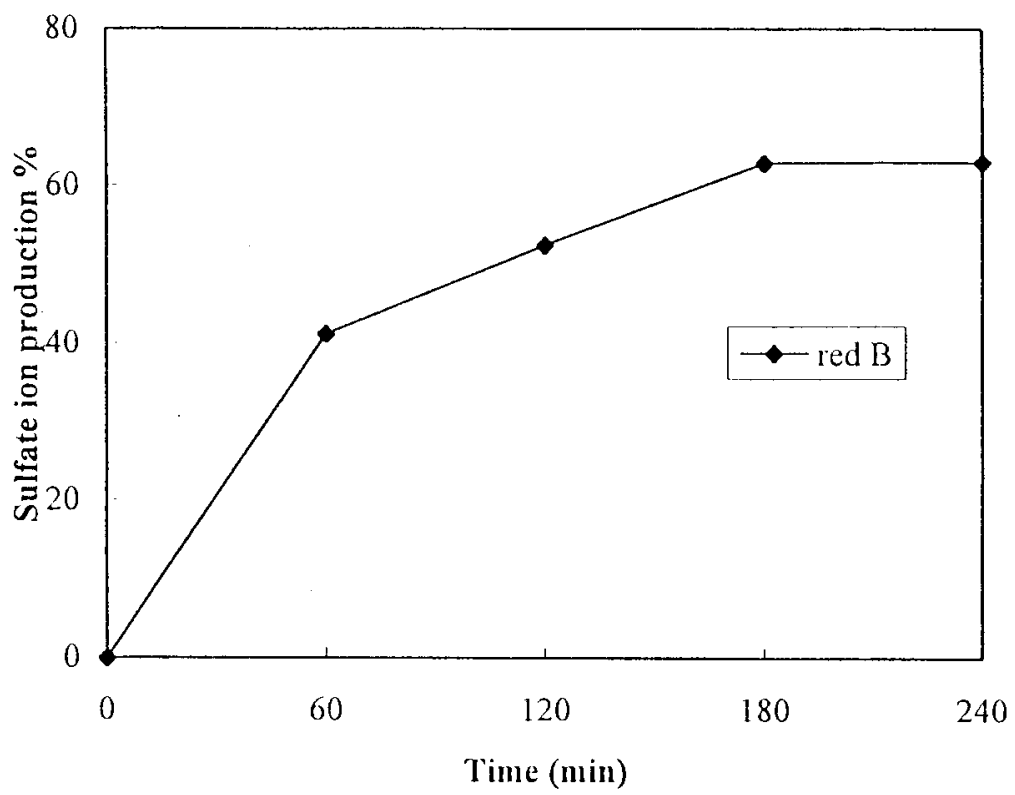

Fig. 5. Sulfate ion production of acid red B during $4 \mathrm{~h}$ of photocatalytic oxidation.

ent substitute groups of chloride and sulfonic. The different decolorization rates and TOC decreasing rates of both dyes shown in Figs 1 and 2 indicate that the sulfonic-substituted dye is more reactive than the chloride-substituted dye in the photocatalytic process.

\section{SUMMARY AND CONCLUSION}

This study demonstrates that certain commercial dyes with different structure and different substitute groups can be decolorized and mineralized by solar photocatalysis. The experimental results indicate that during the photocatalytic degradation, the decolorization rate is faster than the mineralization rate. For chloride substituted dye, the chloride in the side chain is more active with respect to cleavage than the one connected with the benzene ring. The triazine ring and the groups connected with it are stable in photocatalysis. A naphthalene ring is more stable than benzene. The structures not adjacent to azo bond are more reactive.

Acknowledgements - This research has been supported by the National Natural Foundation of China (No. 29637010; 59878051) and partly supported by the Chinese Academy of Sciences (No: KZ952-S1-231). Liu Nian, a student of Beijing Industrial University, took part in the research within a training program.

\section{REFERENCES}

Al-Ekabi H., Safarzadeh A., Sifton W. and Story J. (1991) Advanced technology for water purification by hetero- geneous photocatalysis. Int. J. Environ. Pollut. 1, 125 136.

Blake D. M. (1994) Bibliography of work on the photocatalytic removal of hazardous compounds from water and air. National Renewable Energy Laboratory, Golden, $\mathrm{CO}$.

Daoxin Y., Shugui D. and Huasheng X. (1994) Photocatalytic decolorization of dispersal dyes. $J$. Environ. Sci. 6(2), 244-251.

Hamza A. and Hamoda M. F. (1980) Multiprocess treatment of textile wastewater. In: Proc. 35th Purdue Ind. Waste Conf., West Lafayette, IN.

Hoffmann M. R., Martin S. T., Choi W. and Bahnemann D. W. (1995) Environmental applications of semiconductor photocatalysis. Chem. Rev. 95, 69-96.

Li X. Z. and Zhang M. (1996) Decolorization and biodegradability of dyeing wastewater treated by a $\mathrm{TiO}_{2}$-sensitized photo-oxidation process. Water Sci. Technol. 34(9), 49-55.

Lindner M., Bahnemann D. W., Hirther B. and Grieble W. D. (1995) Solar water detoxification: novel $\mathrm{TiO}_{2}$ powders as highly active photocatalysis. In Solar Engineering, eds W. B. Stine, T. Tanaka and D. E. Claridge, pp. 399-408. American Society of Mechanical Engineers, New York.

Minero C., Pelizzetti E., Malato S. and Blanco J. (1993) Large solar plant photocatalytic water decontamination: degradation of pentachorophenol. Chemosphere 26(12), 2103-2119.

Minero C., Pelizzetti E., Malato S. and Blanco J. (1996) Large solar plant photocatalytic water decontamination: effect of operational parameters. Solar Energy 56(5), $421-428$.

Sheng H. L. and Chi M. L. (1993) Treatment of textile waste effluents by ozonation and chemical coagulation. Water Res. 27(12), 1743-1748.

Souther R. H. and Alspaugh T. A. (1957) Textile waste treatment studies. J. Water Pollut. Control Fed. 29, 804. 